\title{
Correlation of Incident Potentially Inappropriate Medication Prescriptions and Hospitalization: An Analysis Based on the PRISCUS List
}

\author{
Frank Henschel $^{1} \cdot$ Marcus Redaelli $^{1,3} \cdot$ Martin Siegel $^{2} \cdot$ Stephanie Stock $^{1}$
}

Published online: 13 August 2015

(c) The Author(s) 2015. This article is published with open access at Springerlink.com

\begin{abstract}
Background Multimorbidity and polypharmacy represent a major problem for elderly patients. Potentially inappropriate medication (PIM) use is highly prevalent among the elderly. PIMs are considered high-risk drugs and are suspected to be responsible for adverse drug events (ADEs) leading to hospitalization.

Objective The objective of this study was to determine hospitalization rates related to selected ADEs in elderly patients with an incident prescription of a PIM as defined by the PRISCUS list. A second objective was to identify other factors independently associated with hospitalization. Methods We retrospectively analysed a full census of pharmaceutical claims, from one of the largest public sickness funds in Germany, for 647,073 patients aged $\geq 65$ years in 2010, the year of publication of the PRISCUS list. Patients who received an incident PIM in 2010 were assigned to the intervention group. Propensity score matching was used to build a control group of patients at a comparable risk level who received an incident equivalent non-PIM. The risk of hospitalization due to PIM
\end{abstract}

Frank Henschel

frank.hen@gmx.de

Stephanie Stock

stephanie.stock@uk-koeln.de

1 Institute for Health Economics and Clinical Epidemiology (IGKE), Cologne University Hospital, Gleueler Strasse 176-178, 50935 Köln, Germany

2 Department of Health Care Management, Technische Universität Berlin, Strasse des 17. Juni 135, 10623 Berlin, Germany

3 Institute of General Practice, Faculty of Medicine, University of Düsseldorf, Moorenstrasse 5, 40225 Düsseldorf, Germany prescription was estimated via the odds ratio (OR). Risk factors were analysed via logistic regression models.

Results The results showed significantly more ADEs in the PIM group. The OR for hospitalization was 1.54 [95\% confidence interval (CI) 1.23-1.93] for patients receiving any PIM compared with those who received a non-PIM. This trend remained stable [OR 1.46 (95 \% CI 1.16-1.84)] after adjustment for relevant covariates in the logistic regression models showing ORs for each risk factor. Besides PIMs, common risk factors such as greater age, comorbidity and specific drug classes were significantly responsible for hospitalization.

Conclusion PIMs (as defined by the PRISCUS list) are associated with high rates of ADEs associated with hospitalization. Our study suggests that PIM reduction may result in a lower risk of hospitalization in the elderly.

\section{Key Points}

Prescription of potentially inappropriate medication (PIM) leads to a significant increase in adverse drug events in the elderly.

Elderly patients taking PIMs are at increased risk of PIM-related hospitalization.

Other common risk factors for an increased risk of hospitalization are greater age, comorbidity and use of cardiovascular drugs.

\section{Introduction}

Adverse drug events (ADEs) cause up to $6 \%$ of all hospitalizations in industrialized countries [1-4]. In particular, frail elderly patients are at risk because of age-related 
physiological impairments, concomitant comorbidities and polypharmacy. Pharmacokinetic and pharmacodynamic alterations in the elderly may enhance sensitivity to specific drugs and make the elderly more vulnerable to ADEs [5].

Evidence-based guidelines mainly address single indications only and often recommend treatment with drug combinations. Therefore, multimorbidity results in multiple drug treatment, which often generates further medication via the so-called prescribing cascade phenomenon, meaning prescription of extra medications aimed at relieving the symptoms of unrecognized ADEs [6]. The lack of clinical trial data on the efficacy and safety of drugs in elderly patients contributes to this development $[7,8]$. More than a quarter of hospital admissions in elderly patients that are due to ADEs are judged to have been preventable if more caution had been exercised in drug prescription $[4,9,10]$. One approach to reducing ADEs in the elderly is development of explicit recommendations for drugs to be avoided. The first structured approach is the Beers Criteria, which specify "potentially inappropriate medications" (PIMs) for patients aged $\geq 65$ years. PIMs are defined as drugs whose risks outweigh their clinical benefits, particularly when there is a safer or more effective alternative drug available for the same condition [11].

To take into consideration country-specific characteristics, PIM lists have been developed in several countries (e.g. Canada [12], France [13], Ireland [14] and Sweden [15]). In Germany, the so-called PRISCUS list was published in 2010 [16]. It comprises drugs that should generally be avoided and names alternatives with a better benefit-to-risk ratio in the elderly. The PRISCUS list uses the four most important international PIM lists as a reference $[12,13,17,18]$. More than $60 \%$ of the drugs in the PRISCUS list can be found in one of these other lists, which include a common core set of medications [19]. Yet prescription of PIMs is still highly prevalent across health care systems [11, 20, 21], with an international median prevalence rate of $20.5 \%$ in primary care [22]. For example, in Germany, one in four elderly patients receives at least one PIM as defined by the PRISCUS list (PRISCUS-PIM) [23, 24].

Although a significant association between prescription of PIMs and health outcomes is expected, clear evidence of causality is missing. Several systematic reviews have come to the conclusion that there is only weak evidence of an association between PIMs and adverse patient outcomes, and they have emphasized that further research is needed $[11,19,25,26]$. The Cochrane Collaboration assessed the grade for the quality of evidence as being "very low" [27], but to conduct randomized controlled trials (as the clinical gold standard), with randomization of older patients to receive a potentially high-risk drug, would be inappropriate. Therefore, other study designs are necessary.
Many earlier studies had limitations with regard to their data and methods. Important confounders such as comorbidity and temporal relationships between PIM use and outcomes were not taken into account, the samples were small, or the samples did not represent the general population.

This retrospective cohort study investigated hospitalization rates related to PIM prescription in the elderly. Additionally, other factors independently associated with hospitalization in the elderly were analysed.

\section{Methods}

\subsection{Data Source}

We analysed a full census of all insured patients aged $\geq 65$ years from one of the largest public sickness funds in Germany [Allgemeine Ortskrankenkasse (AOK) Rheinland-Hamburg], which insures 2.8 million people. It reflects a region of Germany of about 10 million people, including rural and urban areas, of whom approximately $30 \%$ are insured by this statutory health insurance organization. The observation period was the year 2010 to ensure we had the latest data without major changes in prescribing behaviour after the PRISCUS list was published. The data were anonymized. The following characteristics of the insured persons were available for this study: age; sex; time insured; German modification of the International Classification of Diseases 10th edition (ICD10GM) coded diagnoses for ambulatory care, hospital stay or long-stay nursing care; and ambulatory drug prescription.

\subsection{Potentially Inappropriate Medications According to the PRISCUS List}

Identification of PIM prescriptions was based on the PRISCUS list [16], which includes 18 therapeutic groups and 83 drugs. It specifies drugs to avoid; drugs to avoid, depending on the prescribed dose (nine drugs); and drugs with an arbitrary formulation (two drugs). For these 11 drugs, we used the central pharmaceutical number, which categorizes medications exactly into name, dose and size, to distinguish PIMs and non-PIMs. The daily defined dose was not assessed, since some medications are taken only for a limited period of time and we could not assess whether the patient took the medication, split it or took more than the normal dosage. An incident non-PIM was defined as a drug from the equivalent 18 medication groups (see Fig. 1) defined via Anatomical Therapeutic Chemical Classification System (ATC) coding (e.g. ATC codes $\mathrm{N} 06 \mathrm{~A}=$ antidepressants and $\mathrm{N} 02=$ analgesics $).$ This 


18Drug classes:
Analgesics
Antidementia
Antidepressants
Antiemetics
Antiepileptics
Antihistamines
Antiparkinsonian
Antipsychotics a-/tvpical
Cardiovascular drugs (2)
Laxatives
Migraine agents
Muscle relaxants
Platelet aggregation
inhibitors
Sedatives, hypnotics
Svstemic antibiotics
Urologic spasmolytics

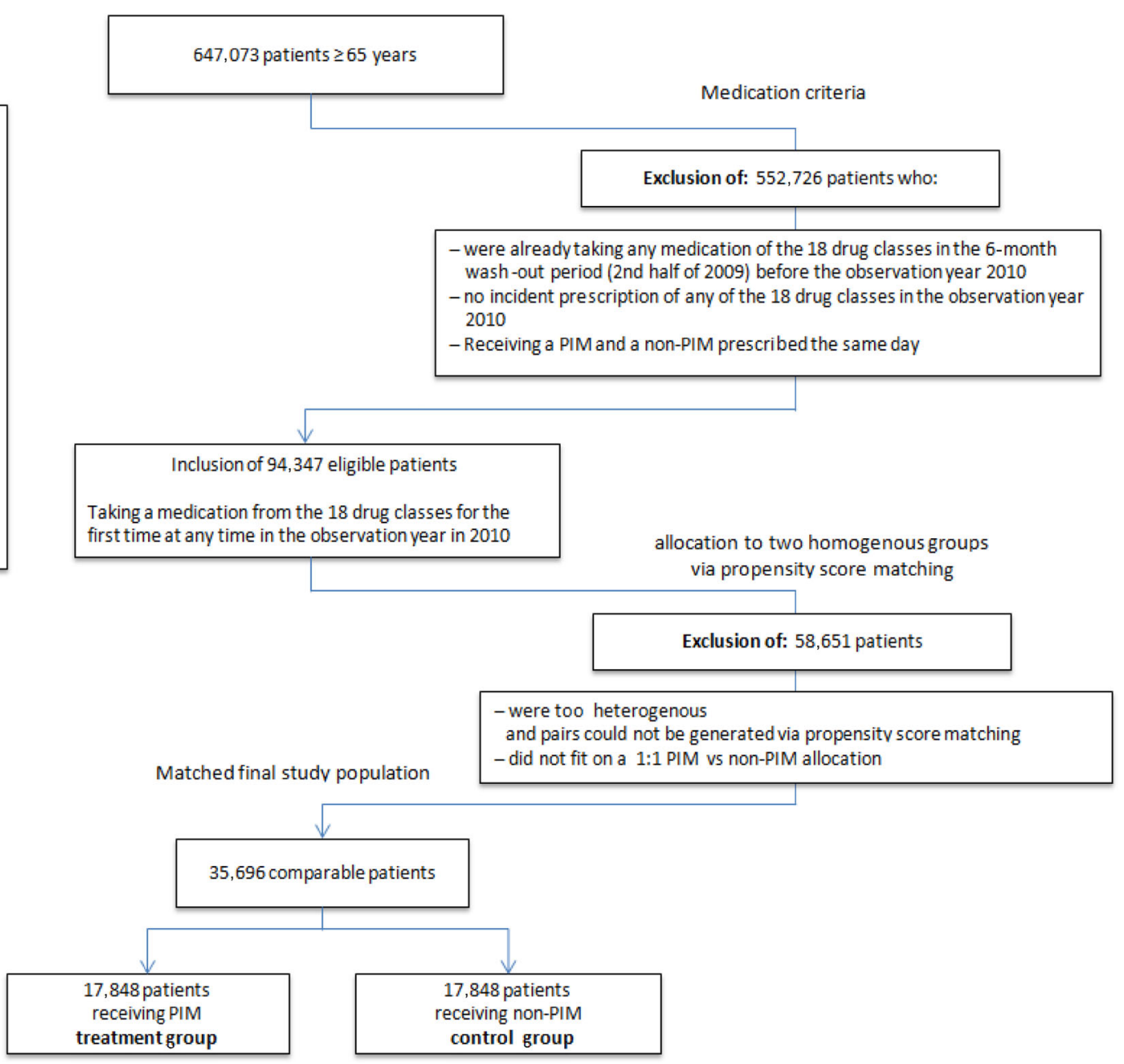

Fig. 1 Patient flow: selection of the final study population. a-/typical typical and atypical, PIM potentially inappropriate medication

restriction was done to exclude cases such as use of new toxic oncological drugs in the non-PIM group. Examples of non-PIMs for the indication "cardiovascular diseases" are bisoprolol or amlodipine, whereas acetyldigoxin and doxazosin are cardiovascular drugs included in the PRISCUS list.

\subsection{Study Population}

This retrospective cohort study was based on claims data from 647,073 insured patients aged $\geq 65$ years.

Insured patients with PIM prescriptions were identified via the ATC. Those included in the study were all patients with at least one incident PIM prescription during the study year. Incident drug prescription was defined as prescription of a PIM during the study period AND either no PIM prescription or a non-PIM equivalent prescription within 6 months prior to the study period (the second half of 2009). Patients receiving a PIM or a non-PIM equivalent within 6 months preceding the study period or receiving simultaneous PIM and non-PIM prescriptions were excluded from the study. The time frame of 6 months was chosen to ensure that the drug was fully eliminated and to ensure reversal of any effect of tolerance. Matching variables were age, sex, drug classes, comorbidity and hospitalization in the preceding quarter, as well as insulin and phenprocoumon prescription. We included phenprocoumon (the European equivalent of warfarin) and insulin because these drugs and digoxin (a PIM) have been held responsible for many hospitalizations in previous studies [28]. The maximum tolerance for matching was 0.001 , based on linear predictions from a logistic regression. Figure 1 describes the selection of the final study population.

\subsection{Assessment of Hospitalization Risk Associated with PIM Prescribing}

To ensure a temporal relationship between hospital admission and PIM prescription, hospitalization within 30 days after the first prescription of a new PIM was the 
main outcome variable $[29,30]$. The 30 -day observation period was chosen to ensure a temporal relationship to the dispensing, as drugs often lead to adverse reactions shortly after their first application [29, 30]. We based the length of this time period on a set of prior studies (e.g. Singh et al. [31] and Lau et al. [32]) to ensure that the temporal relationship was maintained in the analyses. Choosing a shorter time period might have led to underestimation of the potential adverse effects, as some long-term effects may occur only after a longer period of time. Likewise, choice of a longer time period would have incurred a risk of overestimation of potential adverse effects, as ADEs usually occur within the first weeks of drug intake [33, 34]. We performed some sensitivity analyses using a 5-day period and a 90-day period. The results changed only marginally when the time lag was altered, suggesting that the method was fairly robust.

Hospital admission was counted as ADE related if the main diagnosis responsible for the admission was potentially related to ADEs, as proposed and validated by Stausberg et al. The diagnoses suggested by Stausberg have shown good results in representing plausible adverse events linked to drugs [35-37]. Under real-life conditions, detection of ADEs in elderly patients suffering from comorbidities and taking several drugs is complicated. Likewise, in our retrospective study, it was not possible to delineate a causal association between the hospitalization and the newly dispensed drug.

\subsection{Statistical Analysis}

Propensity score matching (PSM) was used to build a risk-adjusted control group from administrative data. PSM mimics randomization for observed variables. Propensity scores for matching are obtained through logistic regression analysis weighing covariates for the risk of hospitalization. In addition, the risk of PIM prescription and each covariate (e.g. drug classes responsible for hospital admissions due to ADEs) were estimated using logistic regression (Table 2). Independent variables were age, sex, number of drugs, classes of drugs, comorbidity and hospitalization within 3 months preceding the study period, as well as insulin or phenprocoumon dispensing during the same time. The Charlson comorbidity index (CCI) was used to adjust for comorbid conditions/burden of disease [38]. To verify this ICD-10 diagnoses, both outpatient and inpatient data were used for the CCI. Standard errors were computed using the robust Huber-White sandwich estimator. All analyses were performed using Stata 10.1 software.

\section{Results}

\subsection{Final Study Population}

Our final study cohort comprised 35,696 patients. PSM led to comparable study groups, each with a size of 17,848 patients. Table 1 shows the characteristics of the final study population. These patients received a drug from one of the 18 therapeutic groups for the first time in the observation year, 2010. About half of the study population had no comorbidity as defined by the CCI. Nearly $20 \%$ were hospitalized within 90 days preceding the intake of any new medication, and $10 \%$ had a diagnosis potentially caused by an adverse drug reaction, which resulted in hospitalization. Most incident prescriptions in 2010 belonged to the following therapeutic classes: analgesics $(41.66 \%)$, cardiovascular medications $(36.14 \%)$, antibiotics $(17.44 \%)$, antidepressants $(5.73 \%)$, platelet aggregation inhibitors $(4.43 \%)$ and sedatives $(2.85 \%)$.

\subsection{Risk of Hospitalization}

The incidence of hospitalization differed significantly between groups, with 127 cases $(39.44 \%)$ in the control group and 195 cases $(60.56 \%)$ in the intervention group. The odds ratio (OR) for hospitalization was 1.54 [95\% confidence interval (CI) 1.23-1.93] for those receiving PIMs in comparison with those receiving equivalent nonPIMs.

Multivariate regression analyses assessed the influence of different covariates on hospitalization rates. Table 2 shows that the odds were significantly increased with PIM prescription [OR 1.46 (95\% CI 1.16-1.84)]. Other risks for hospitalization were greater age, higher CCI scores (with the exception of a CCI score of 5), preceding events of hospitalization [OR 1.69 (95\% CI 1.32-2.16)] and two drug classes: antihistamines [OR $2.47 \quad(95 \% \mathrm{CI}$ 1.30-4.71)] and cardiovascular drugs [OR $1.84(95 \% \mathrm{CI}$ 1.40-2.41)].

The main diagnoses responsible for hospitalization were either directly or indirectly related to the cardiovascular system, such as 'atrial fibrillation and flutter', 'atrioventricular block', 'volume depletion' or 'hypo-osmolality and hyponatraemia', which might have resulted in negative effects on the heart (Table 3).

\section{Discussion}

In this cohort study, we found a significant positive association between incident PIM prescription and subsequent risk of hospitalization. After mimicking randomization via 
Table 1 Characteristics of the final matched study population with incident PIM use and no PIM use

\begin{tabular}{llrr}
\hline Characteristic & Non-PIM & PIM & Total \\
\hline Patients $[N(\%)]$ & $17,848(50.00)$ & $17,848(50.00)$ & 35,696 \\
Sex $[N(\%)]$ & & & \\
Female & $11,030(50.56)$ & $10,785(49.44)$ & 21,815 \\
Male & $6818(49.12)$ & $7063(50.88)$ & 13,881 \\
Age $[N(\%)]$ & & & \\
65-69 years & $3937(49.80)$ & $3969(50.20)$ & 7906 \\
$70-74$ years & $5050(49.75)$ & $5100(50.25)$ & 10,150 \\
$75-79$ years & $3857(51.65)$ & $3611(48.35)$ & 7468 \\
$80-84$ years & $2752(48.13$ & $2966(51.87)$ & 5718 \\
$85-89$ years & $1503(51.86)$ & $1395(48.14)$ & 2898 \\
$90-94$ years & $531(48.67)$ & $560(51.33)$ & 1091 \\
$95+$ years & $218(46.88)$ & $247(53.12)$ & 465 \\
Charlson comorbidity index score $[N(\%)]$ & & & \\
0 & $9675(50.65)$ & $9428(49.35)$ & 19,103 \\
1 & $3580(50.33)$ & $3533(49.67)$ & 7113 \\
2 & $2051(49.53)$ & $2090(50.47)$ & 4141 \\
3 & $1113(48.97)$ & $1160(51.03)$ & 2273 \\
4 & $990(47.55)$ & $1092(52.45)$ & 2082 \\
$5+$ & $439(44.61)$ & $545(55.39)$ & 984 \\
Adverse drug event: hospitalization $[N(\%)]$ & $127(39.44)$ & $195(60.56)$ & 322 \\
OR for hospitalization $(95 \%$ CI) & Reference & $1.54(1.23-1.93)$ & \\
\hline
\end{tabular}

$C I$ confidence interval, $O R$ odds ratio, PIM potentially inappropriate medication
PSM, patients with a PIM prescription had a 1.54-fold higher risk (95\% CI 1.23-1.93) of being hospitalized within 30 days after the first dispensing of the PIM, in comparison with the control group.

Additional multivariate regression analyses showed that other factors associated with hospitalization were age and CCI score. This finding correlates with PIM prescribing patterns, correlating positively with age, the number of comorbidities and female sex [39-41]. Incident prescriptions of two drug classes-antihistamines and cardiovascular drugs - were associated with hospitalization, whereas those for other drug classes were not statistical significant. This was probably due to the study design and the small number of remaining cases.

Other drugs that made up large proportions of the incident prescriptions, e.g. analgesics, with typical side effects on the gastrological, nephrological and cardiovascular systems, did not show statistically significant associations. However, these medications have been positively correlated with hospital admissions [42]. The reason why we could not display this correlation in our study was probably due to the study design, since classical analgesic-induced ADEs, such as severe gastric ulcers, would tend to occur after our study's cut-off time of 30 days [43]. This is generally the case, with some ADEs evolving at a later stage being missed. Further research analysing specific drug classes, with larger numbers of cases and designed particularly for particular drug classes and indications, is necessary for clarification [44].

\subsection{Results in Relation to Other Studies}

It is difficult to compare prior studies with our study, as in many of those studies the sample sizes were small and not representative, there was no adjustment for important covariates included in the analyses, or a temporal relationship between drug use and ADEs was not taken into account [11, 19]. Even differences in coding and identification of ADEs need to be considered. Most mainly US studies have measured hospitalizations, either in general in the case of PIM studies, or after coding as ICD Y diagnoses in other studies. These $\mathrm{Y}$ codes include 'drugs, medicaments and biological substances causing adverse effects in therapeutic use' and suggest a causal relationship to ADE-related hospitalizations.

For example, Lau et al. (OR 1.27) and Dedhiya et al. (OR 1.27) also identified hospitalizations in general and reported findings similar to those in our study, though those studies had some of the previously mentioned methodological issues [32, 45]. 
Table 2 Results of the logistic regression model describing the factors for each covariate associated with hospitalization

\begin{tabular}{lcr}
\hline & OR $(95 \%$ CI $)$ & $P$ value \\
\hline First PIM & $1.46(1.16-1.84)$ & $<0.001$ \\
Age group & 1 (reference) & \\
65-69 years & $1.34(0.90-1.99)$ & 0.145 \\
70-74 years & $1.83(1.23-2.70)$ & 0.003 \\
75-79 years & $2.15(1.45-3.20)$ & $<0.001$ \\
80-84 years & $2.18(1.38-3.45)$ & $<0.001$ \\
85-89 years & $2.02(1.09-3.75)$ & 0.026 \\
90-94 years & $2.47(1.08-5.65)$ & 0.032 \\
95+ years & & \\
Sex & $1.00($ reference $)$ & \\
Female & $0.80(0.63-1.01)$ & 0.058 \\
Male & & \\
Charlon Combidi & &
\end{tabular}

Charlson Comorbidity Index score

\begin{tabular}{|c|c|c|}
\hline 0 & 1.00 (reference) & \\
\hline 1 & $2.49(1.73-3.58)$ & $<0.001$ \\
\hline 2 & $3.32(2.26-4.86)$ & $<0.001$ \\
\hline 3 & $5.53(3.74-8.20)$ & $<0.001$ \\
\hline 4 & $9.28(6.48-13.28)$ & $<0.001$ \\
\hline 5 & $7.31(4.53-11.80)$ & $<0.001$ \\
\hline \multicolumn{3}{|l|}{ Medication } \\
\hline Analgesics & $0.87(0.66-1.16)$ & 0.345 \\
\hline Antidementia agents & $0.31(0.08-1.29)$ & 0.108 \\
\hline Antidepressants & $1.48(0.93-2.35)$ & 0.097 \\
\hline Antiemetics & $0.84(0.25-2.81)$ & 0.771 \\
\hline Antiepileptics & $1.86(0.93-3.68)$ & 0.077 \\
\hline Antihistamines & $2.47(1.30-4.71)$ & 0.006 \\
\hline Antiparkinsonian agents & $1.68(0.52-5.47)$ & 0.387 \\
\hline Antipsychotics, a-/typical & $1.17(0.65-2.09)$ & 0.6 \\
\hline Cardiovascular drugs & $1.84(1.40-2.41)$ & $<0.001$ \\
\hline Laxatives & $1.03(0.34-3.14)$ & 0.962 \\
\hline Migraine agents & $1.40(1.75-3.63)$ & 0.362 \\
\hline Muscle relaxants & $1.19(0.28-5.05)$ & 0.81 \\
\hline Platelet aggregation inhibitors & $0.78(0.49-1.23)$ & 0.285 \\
\hline Sedatives, hypnotics & $1.66(0.94-2.92)$ & 0.078 \\
\hline Systemic antibiotics & $1.16(0.82-1.64)$ & 0.405 \\
\hline Urological spasmolytics & $0.83(0.26-2.67)$ & 0.753 \\
\hline \multicolumn{3}{|l|}{ Preceding medication } \\
\hline Insulin & $0.58(0.37-0.91)$ & 0.017 \\
\hline Phenprocoumon & $2.95(1.71-5.09)$ & $<0.001$ \\
\hline \multicolumn{3}{|l|}{ Preceding event } \\
\hline Hospitalization & $1.69(1.32-2.16)$ & $<0.001$ \\
\hline
\end{tabular}

a-/typical typical and atypical, $C I$ confidence interval, $O R$ odds ratio, $P I M$ potentially inappropriate medication

Budnitz et al. analysed emergency hospitalizations caused by ADEs [28] identified via ICD Y codes.

The main drugs causing ADEs in these studies were warfarin $(17.3 \%)$, insulin $(13 \%)$ and digoxin $(3.2 \%)$.
Conversely, PIMs (as defined by the Beers Criteria of 2003) played only a small role $(3.6 \%)$.

It is not surprising that this kind of identification primarily captures cases that are obvious and easy to detect, such as insulin overdosing in cases of hypoglycaemia or a pathological international normalized ratio (INR) in cases of bleeding associated with warfarin. But this kind of measurement tends to underestimate many ADEs that are more ambiguous-for example, anticholinergic side effects (such as those influencing the heart rhythm or causing dizziness), for which it is harder to prove causality, especially in multimorbid patients [46]. But anticholinergic and sedative medications are a major part of PIM lists and are well known to be associated with poorer performance on physical mobility and cognitive tasks [47]. In a systematic review of ambulatory-based studies, for example, ADEs resulted most frequently in central nervous system (CNS) symptoms (25.1\%), followed by gastrointestinal symptoms (22.7\%) and electrolyte/renal symptoms (12.4\%) [2]. Transferred to our study results, diagnoses such as 'atrial fibrillation and flutter' may be associated with side effects of a new anticholinergic PIM such as an antidepressant or neuroleptic, and alpha blockers such as doxazosin may be responsible for 'orthostatic hypotension'.

We wanted to learn from previous studies, and we refined their approaches by building comparable groups via PSM and implementing a temporal relationship to the new PIM drug intake. We detected hospitalizations in general but adapted detection to country-specific conditions by limiting our analysis to particular diagnoses that are potentially related to ADEs, as defined by Stausberg, for a retrospective study design. Our intent was to reduce bias as much as possible [48].

Our results matched those of newer studies using outcome detection in general, which achieved similar results regarding PIM and hospitalization. Using the socalled Screening Tool of Older Persons' Potentially Inappropriate Prescriptions (STOPP) criteria, developed by Gallagher et al. in Ireland, Hamilton et al. found significantly higher rates of hospitalization in patients receiving PIMs (OR 1.85) and positive effects of PIM lists $[14,49,50]$.

A study design similar to ours was used by Price et al. who analysed the health profiles of 383,150 hospitalized subjects, showing that overall PIM exposure was associated with an elevated risk of hospitalization (adjusted OR 1.18) [51]. This trend was confirmed in a recently published prospective study in Italian hospitals [52]. A recent study in Switzerland analysed determinants of PRISCUS-PIMs and revealed that PIM use was significantly associated with hospitalization [39]. 
Table 3 Diagnoses registered at the time of hospitalization

\begin{tabular}{|c|c|c|c|c|c|}
\hline \multicolumn{3}{|c|}{ Non-PIM } & \multicolumn{3}{|l|}{ PIM } \\
\hline $\begin{array}{l}\text { ICD } \\
\text { code }\end{array}$ & $\begin{array}{l}\text { Patients } \\
(N)\end{array}$ & ICD code description & $\begin{array}{l}\text { ICD } \\
\text { code }\end{array}$ & $\begin{array}{l}\text { Patients } \\
(N)\end{array}$ & ICD code description \\
\hline A047 & 3 & Enterocolitis due to Clostridium difficile & A047 & 8 & Enterocolitis due to Clostridium difficile \\
\hline D690 & 1 & Allergic purpura & E86 & 19 & Volume depletion \\
\hline E86 & 9 & Volume depletion & E870 & 1 & Hyperosmolality and hypernatraemia \\
\hline E876 & 1 & Hypokalaemia & E871 & 4 & Hypo-osmolality and hyponatremia \\
\hline F115 & 1 & $\begin{array}{l}\text { Mental and behavioural disorders due to use of } \\
\text { opioids }\end{array}$ & E875 & 1 & Hyperkalaemia \\
\hline $\mathrm{I} 260$ & 6 & $\begin{array}{l}\text { Pulmonary embolism with mention of acute cor } \\
\text { pulmonale }\end{array}$ & H539 & 1 & Visual disturbance, unspecified \\
\hline I269 & 4 & $\begin{array}{l}\text { Pulmonary embolism without mention of acute } \\
\text { cor pulmonale }\end{array}$ & $\mathrm{I} 260$ & 3 & $\begin{array}{l}\text { Pulmonary embolism with mention of acute cor } \\
\text { pulmonale }\end{array}$ \\
\hline I441 & 1 & Atrioventricular block, second degree & I 269 & 2 & $\begin{array}{l}\text { Pulmonary embolism without mention of acute cor } \\
\text { pulmonale }\end{array}$ \\
\hline I442 & 2 & Atrioventricular block, complete & & 1 & $\begin{array}{l}\text { Pulmonary embolism without mention of acute cor } \\
\text { pulmonale }\end{array}$ \\
\hline I470 & 1 & Re-entry ventricular arrhythmia & I441 & 3 & Atrioventricular block, second degree \\
\hline I471 & 1 & Supraventricular tachycardia & I442 & 2 & Atrioventricular block, complete \\
\hline I 4810 & 26 & Atrial fibrillation and flutter & I447 & 1 & Left bundle-branch block, unspecified \\
\hline I490 & 1 & Ventricular fibrillation and flutter & I471 & 1 & Supraventricular tachycardia \\
\hline I495 & 3 & Sick sinus syndrome & I472 & 1 & Ventricular tachycardia \\
\hline I499 & 1 & Cardiac arrhythmia, unspecified & $\mathrm{I} 4810$ & 61 & Atrial fibrillation and flutter \\
\hline I610 & 1 & $\begin{array}{l}\text { Intracerebral haemorrhage in hemisphere, } \\
\text { subcortical }\end{array}$ & $\mathrm{I} 495$ & 3 & Sick sinus syndrome \\
\hline I612 & 1 & $\begin{array}{l}\text { Intracerebral haemorrhage in hemisphere, } \\
\text { unspecified }\end{array}$ & I616 & 1 & Intracerebral haemorrhage, multiple localized \\
\hline I613 & 1 & Intracerebral haemorrhage in brain stem & I 800 & 1 & $\begin{array}{l}\text { Phlebitis and thrombophlebitis of superficial vessels of } \\
\text { lower extremities }\end{array}$ \\
\hline I619 & 1 & Intracerebral haemorrhage, unspecified & I802 & 3 & Other venous embolism and thrombosis \\
\hline I801 & 2 & Phlebitis and thrombophlebitis of femoral vein & I 808 & 1 & Phlebitis and thrombophlebitis of other sites \\
\hline I 802 & 2 & Other venous embolism and thrombosis & I951 & 5 & Orthostatic hypotension \\
\hline I 803 & 1 & $\begin{array}{l}\text { Phlebitis and thrombophlebitis of lower } \\
\text { extremities, unspecified }\end{array}$ & K290 & 4 & Acute haemorrhagic gastritis \\
\hline I808 & 1 & Phlebitis and thrombophlebitis of other sites & K521 & 1 & Toxic gastroenteritis and colitis \\
\hline I951 & 2 & Orthostatic hypotension & K922 & 4 & Gastrointestinal haemorrhage, unspecified \\
\hline K290 & 6 & Acute haemorrhagic gastritis & N178 & 4 & Other acute renal failure \\
\hline K717 & 1 & $\begin{array}{l}\text { Toxic liver disease with fibrosis and cirrhosis of } \\
\text { liver }\end{array}$ & N179 & 7 & Acute renal failure, unspecified \\
\hline K922 & 5 & Gastrointestinal haemorrhage, unspecified & N184 & 3 & Chronic kidney disease, stage 4 \\
\hline N178 & 2 & Other acute renal failure & N185 & 3 & Chronic kidney disease, stage 5 \\
\hline N179 & 7 & Acute renal failure, unspecified & N189 & 1 & Chronic kidney disease, unspecified \\
\hline N183 & 1 & Chronic kidney disease, stage $1-5$ & R060 & 2 & Dyspnoea \\
\hline N185 & 1 & Chronic kidney disease, stage 5 & R11 & 5 & Nausea and vomiting \\
\hline R060 & 2 & Dyspnoea & R33 & 1 & Retention of urine \\
\hline R11 & 1 & Nausea and vomiting & R400 & 1 & Somnolence \\
\hline R21 & 1 & Rash and other nonspecific skin eruption & $\mathrm{R} 42$ & 3 & Dizziness and giddiness \\
\hline R33 & 1 & Retention of urine & R51 & 2 & Headache \\
\hline $\mathrm{R} 42$ & 1 & Dizziness and giddiness & $\mathrm{R} 55$ & 21 & Syncope and collapse \\
\hline R451 & 1 & Restlessness and agitation & $\mathrm{T} 460$ & 1 & Cardiac-stimulant glycosides and drugs of similar action \\
\hline R51 & 1 & Headache & $\mathrm{T} 783$ & 1 & Angioneurotic oedema \\
\hline \multirow[t]{2}{*}{ R55 } & 9 & Syncope and collapse & & & \\
\hline & 1 & Syncope and collapse & & & \\
\hline
\end{tabular}


Table 3 continued

\begin{tabular}{|c|c|c|c|c|}
\hline \multicolumn{3}{|c|}{ Non-PIM } & \multicolumn{2}{|l|}{ PIM } \\
\hline $\begin{array}{l}\text { ICD } \\
\text { code }\end{array}$ & $\begin{array}{l}\text { Patients } \\
(N)\end{array}$ & ICD code description & $\begin{array}{l}\text { ICD } \\
\text { code }\end{array}$ & $\begin{array}{l}\text { Patients } \text { ICD code description } \\
(N)\end{array}$ \\
\hline $\mathrm{T} 400$ & 1 & Opioid & & \\
\hline T424 & 1 & Benzodiazepines & & \\
\hline T464 & 1 & Angiotensin-converting-enzyme inhibitors & & \\
\hline T783 & 2 & Angioneurotic oedema & & \\
\hline Total & 119 & & Total & 187 \\
\hline
\end{tabular}

PIM potentially inappropriate medication

\subsection{Strengths and Limitations of This Study}

The strengths of this study were the large and representative sample and the comprehensiveness of the data. Our complex method differed from those used in other studies analysing PIMs and clinical outcomes in various respects. First, to fulfil important aspects of the Naranjo algorithm in the identification of an ADE, we focused on analysing hospitalizations and their temporal relationship to receiving a new medication [53]. Second, we chose an observation time period of 30 days after intake of the new medication, since most ADEs occur soon after the initial prescribing, when the patient is not yet accustomed to the medication $[29,30]$, as in the case of falls $[33,34,54]$. Also, by implementing a washout period and using PSM, we reduced selection bias and potential unintended influences of confounders.

Since previous studies found differing results, depending on whether matching was done or not, our intent was to reduce bias as much as possible [48], although this resulted in a decreased study sample. Our goal was to give precision priority over quantity.

Besides its strengths, our study suffered from some of the common limitations of a retrospective design. Although control for a number of potential confounders was possible by matching, uncontrolled confounding due to missing clinical information and other unknown covariates is likely to have occurred, i.e. our analyses were not suited to studying dose dependency of subsequent ADEs, nor did we have information about the influence of over-the-counter (OTC) drugs on outcomes. Patients taking PIMs have been shown to have a slightly worse health status, which was partly accounted for by PSM and was therefore also reflected in our study population. The aforementioned advantage of analysing new use of PIMs could conversely have been a disadvantage, since some ADEs might develop only after more than 30 days, as discussed previously. Therefore, some ADEs might not have been detected. In addition, choosing to consider only individuals with a PIM-free period prior to the study may have resulted in a somehow healthier population in comparison with the average patient population. However, the CCI scores of our study population were not particularly low and could be judged to be in the average range, in comparison with the populations of other studies. Finally, given the retrospective nature of the study, one cannot conclude certainly if it was the PIM drugs per se that were dangerous for patients or if the PIM prescribing was an indicator of dangerous prescribing. We conclude that the results suggest the presence of a relationship between PIM use and specific ADEs but cannot demonstrate causality.

\subsection{Value of PIM Lists}

PIM lists should not be seen as standalone criteria, nor do they replace individually tailored consideration of risks and benefits for the individual patient. Yet they have to be viewed in contrast to individual medication reviews, which involve a thoroughly active, time-consuming assessment of each medication, after consideration of its indication, effectiveness, dosage and other clinical information to determine its appropriateness $[55,56]$.

PIM lists are universally available, inexpensive and a time-efficient screening tool, which are an important instrument for medical reviews and can be implemented in computer software to support physicians.

This is of special interest, as the mean physician contact times with patients are only 9.0 min in Germany, $11.8 \mathrm{~min}$ in the UK and $20.3 \mathrm{~min}$ in the USA [57]. Hence, hints in computer software may be valuable at the time of prescribing to prevent suboptimal drug choices-for example, through prior physician education [40]. Mattison et al. reported a decrease in PIM prescribing after implementation of an effectively computerized provider order entry warning system [58].

\section{Conclusion}

Use of PIMs in the elderly is a major public health concern. These explicit (criterion-based) PIM lists should not be seen as standalone criteria, nor do they replace individually 
tailored consideration of risks and benefits for the individual patient.

Implicit (judgment-based) criteria might perform better concerning clinical outcomes. However, implicit criteria also require considerable time for assessment of each medication, after consideration of its indication, effectiveness, dosage and other clinical information to determine its appropriateness $[55,56]$. Instead, PIM lists are universally available, inexpensive and a time-efficient screening tool, which are an important instrument for medical reviews and can be implemented in computer software to support physicians.

Our study suggests that elderly patients taking PRISCUS-PIMs are more likely to suffer from ADEs, leading to an increased risk of hospitalization. This study supports the increasing consensus to avoid new prescribing of PIMs [11, $56,59]$.

Acknowledgments The authors are grateful to the statutory health insurance organization Allgemeine Ortskrankenkasse (AOK) Rheinland-Hamburg for providing this comprehensive data set.

\section{Compliance with Ethical Standards}

Funding This research project was funded by the non-profit foundation Dr Werner Jackstädt-Stiftung, (Wuppertal, Germany) (http:// www.jackstaedt-stiftung.de).

Conflict of interest Prof. Stock and Drs. Siegel, Redaelli and Henschel have no conflict of interest.

Ethical issues The authors state that for this retrospective and pseudonymized study, no ethical approval was needed.

Open Access This article is distributed under the terms of the Creative Commons Attribution-NonCommercial 4.0 International License (http://creativecommons.org/licenses/by-nc/4.0/), which permits any noncommercial use, distribution, and reproduction in any medium, provided you give appropriate credit to the original author(s) and the source, provide a link to the Creative Commons license, and indicate if changes were made.

\section{References}

1. Pirmohamed M, James S, Meakin S, Green C, Scott AK, Walley TJ, et al. Adverse drug reactions as cause of admission to hospital: prospective analysis of 18820 patients. BMJ. 2004;329(7456):15-9.

2. Thomsen LA, Winterstein AG, Sondergaard B, Haugbolle LS, Melander A. Systematic review of the incidence and characteristics of preventable adverse drug events in ambulatory care. Ann Pharmacother. 2007;41(9):1411-26.

3. Lazarou J, Pomeranz BH, Corey PN. Incidence of adverse drug reactions in hospitalized patients: a meta-analysis of prospective studies. JAMA. 1998;279(15):1200-5.

4. Thomas EJ, Brennan TA. Incidence and types of preventable adverse events in elderly patients: population based review of medical records. BMJ. 2000;320(7237):741-4.
5. Mangoni AA, Jackson SH. Age-related changes in pharmacokinetics and pharmacodynamics: basic principles and practical applications. Br J Clin Pharmacol. 2004;57(1):6-14.

6. Rochon PA, Gurwitz JH. Optimising drug treatment for elderly people: the prescribing cascade. BMJ. 1997;315(7115):1096-9.

7. Van Spall HG, Toren A, Kiss A, Fowler RA. Eligibility criteria of randomized controlled trials published in high-impact general medical journals: a systematic sampling review. JAMA. 2007;297(11):1233-40.

8. Zulman DM, Sussman JB, Chen X, Cigolle CT, Blaum CS, Hayward RA. Examining the evidence: a systematic review of the inclusion and analysis of older adults in randomized controlled trials. J Gen Intern Med. 2011;26(7):783-90.

9. Ferner RE, Aronson JK. Preventability of drug-related harmspart I: a systematic review. Drug Saf. 2010;33(11):985-94.

10. Gurwitz JH, Field TS, Harrold LR, Rothschild J, Debellis K, Seger AC, et al. Incidence and preventability of adverse drug events among older persons in the ambulatory setting. JAMA. 2003;289(9):1107-16.

11. Spinewine A, Schmader KE, Barber N, Hughes C, Lapane KL, Swine C, et al. Appropriate prescribing in elderly people: how well can it be measured and optimised? Lancet. 2007;370(9582):173-84.

12. McLeod PJ, Huang AR, Tamblyn RM, Gayton DC. Defining inappropriate practices in prescribing for elderly people: a national consensus panel. CMAJ. 1997;156(3):385-91.

13. Laroche ML, Charmes JP, Merle L. Potentially inappropriate medications in the elderly: a French consensus panel list. Eur J Clin Pharmacol. 2007;63(8):725-31.

14. Gallagher P, O'Mahony D. STOPP (screening tool of older persons' potentially inappropriate prescriptions): application to acutely ill elderly patients and comparison with Beers' Criteria. Age Ageing. 2008;37(6):673-9.

15. Fastbom J, Johnell K. National indicators for quality of drug therapy in older persons: the Swedish experience from the first 10 years. Drugs Aging. 2015;32:189-99. doi:10.1007/s40266015-0242-4.

16. Holt S, Schmiedl S, Thurmann PA. Potentially inappropriate medications in the elderly: the PRISCUS list. Dtsch Arztebl Int. 2010;107(31-32):543-51.

17. Beers $\mathrm{MH}$. Explicit criteria for determining potentially inappropriate medication use by the elderly: an update. Arch Intern Med. 1997;157(14):1531-6.

18. Fick DM, Cooper JW, Wade WE, Waller JL, Maclean JR, Beers $\mathrm{MH}$. Updating the Beers criteria for potentially inappropriate medication use in older adults: results of a US consensus panel of experts. Arch Intern Med. 2003;163(22):2716-24.

19. Chang CB, Chan DC. Comparison of published explicit criteria for potentially inappropriate medications in older adults. Drugs Aging. 2010;27(12):947-57.

20. Gallagher P, Lang PO, Cherubini A, Topinkova E, Cruz-Jentoft A, Montero Errasquin B, et al. Prevalence of potentially inappropriate prescribing in an acutely ill population of older patients admitted to six European hospitals. Eur J Clin Pharmacol. 2011;67(11):1175-88.

21. O'Connor MN, Gallagher P, O'Mahony D. Inappropriate prescribing: criteria, detection and prevention. Drugs Aging. 2012;29(6):437-52.

22. Opondo D, Eslami S, Visscher S, de Rooij SE, Verheij R, Korevaar JC, et al. Inappropriateness of medication prescriptions to elderly patients in the primary care setting: a systematic review. PLoS One. 2012;7(8):e43617.

23. Amann U, Schmedt N, Garbe E. Prescribing of potentially inappropriate medications for the elderly: an analysis based on the PRISCUS list. Dtsch Arztebl Int. 2012;109(5):69-75. 
24. Stock S, Redaelli M, Simic D, Siegel M, Henschel F. Risk factors for the prescription of potentially inappropriate medication (PIM) in the elderly: an analysis of sickness fund routine claims data from Germany. Wien Klin Wochenschr. 2014;126(19-20): 604-12.

25. Jano E, Aparasu RR. Healthcare outcomes associated with Beers' Criteria: a systematic review. Ann Pharmacother. 2007;41(3): 438-47.

26. Levy HB, Marcus EL, Christen C. Beyond the Beers criteria: a comparative overview of explicit criteria. Ann Pharmacother. 2010;44(12):1968-75.

27. Patterson SM, Hughes C, Kerse N, Cardwell CR, Bradley MC. Interventions to improve the appropriate use of polypharmacy for older people. Cochrane Database Syst Rev. 2012;(5):CD008165. doi:10.1002/14651858.CD008165.pub2.

28. Budnitz DS, Lovegrove MC, Shehab N, Richards CL. Emergency hospitalizations for adverse drug events in older Americans. N Engl J Med. 2011;365(21):2002-12.

29. Coupland CA, Dhiman P, Barton G, Morriss R, Arthur A, Sach T, et al. A study of the safety and harms of antidepressant drugs for older people: a cohort study using a large primary care database. Health Technol Assess. 2011;15(28):1-202, iii-iv.

30. Ray WA. Evaluating medication effects outside of clinical trials: new-user designs. Am J Epidemiol. 2003;158(9):915-20.

31. Singh S, Chang HY, Richards TM, Weiner JP, Clark JM, Segal JB. Glucagonlike peptide 1-based therapies and risk of hospitalization for acute pancreatitis in type 2 diabetes mellitus: a population-based matched case-control study. JAMA Intern Med. 2013;173(7):534-9.

32. Lau DT, Kasper JD, Potter DE, Lyles A, Bennett RG. Hospitalization and death associated with potentially inappropriate medication prescriptions among elderly nursing home residents. Arch Intern Med. 2005;165(1):68-74.

33. Chang CM, Wu EC, Chang IS, Lin KM. Benzodiazepine and risk of hip fractures in older people: a nested case-control study in Taiwan. Am J Geriatr Psychiatry. 2008;16(8):686-92.

34. Wang PS, Bohn RL, Glynn RJ, Mogun H, Avorn J. Hazardous benzodiazepine regimens in the elderly: effects of half-life, dosage, and duration on risk of hip fracture. Am J Psychiatry. 2001;158(6):892-8.

35. Hohl CM, Karpov A, Reddekopp L, Doyle-Waters M, Stausberg J. ICD-10 codes used to identify adverse drug events in administrative data: a systematic review. J Am Med Inform Assoc. 2014;21(3):547-57.

36. Stausberg J, Hasford J. Identification of adverse drug events: the use of ICD-10 coded diagnoses in routine hospital data. Dtsch Arztebl Int. 2010;107(3):23-9.

37. Stausberg J, Hasford J. Drug-related admissions and hospitalacquired adverse drug events in Germany: a longitudinal analysis from 2003 to 2007 of ICD-10-coded routine data. BMC Health Serv Res. 2011;11:134.

38. Charlson ME, Pompei P, Ales KL, MacKenzie CR. A new method of classifying prognostic comorbidity in longitudinal studies: development and validation. J Chronic Dis. 1987;40(5):373-83.

39. Reich O, Rosemann T, Rapold R, Blozik E, Senn O. Potentially inappropriate medication use in older patients in Swiss managed care plans: prevalence, determinants and association with hospitalization. PLoS One. 2014;9(8):e105425.

40. Zhang YJ, Liu WW, Wang JB, Guo JJ. Potentially inappropriate medication use among older adults in the USA in 2007. Age Ageing. 2011;40(3):398-401.

41. Zhan C, Sangl J, Bierman AS, Miller MR, Friedman B, Wickizer $\mathrm{SW}$, et al. Potentially inappropriate medication use in the community-dwelling elderly: findings from the 1996 Medical Expenditure Panel Survey. JAMA. 2001;286(22):2823-9.
42. Howard RL, Avery AJ, Slavenburg S, Royal S, Pipe G, Lucassen $\mathrm{P}$, et al. Which drugs cause preventable admissions to hospital? A systematic review. Br J Clin Pharmacol. 2007;63(2):136-47.

43. MacDonald TM, Morant SV, Robinson GC, Shield MJ, McGilchrist MM, Murray FE, et al. Association of upper gastrointestinal toxicity of non-steroidal anti-inflammatory drugs with continued exposure: cohort study. BMJ. 1997;315(7119): 1333-7.

44. Price SD, Holman CD, Sanfilippo FM, Emery JD. Impact of specific Beers criteria medications on associations between drug exposure and unplanned hospitalisation in elderly patients taking high-risk drugs: a case-time-control study in Western Australia. Drugs Aging. 2014;31(4):311-25.

45. Dedhiya SD, Hancock E, Craig BA, Doebbeling CC, Thomas J 3rd. Incident use and outcomes associated with potentially inappropriate medication use in older adults. Am J Geriatr Pharmacother. 2010;8(6):562-70.

46. Aparasu RR, Mort JR. Prevalence, correlates, and associated outcomes of potentially inappropriate psychotropic use in the community-dwelling elderly. Am J Geriatr Pharmacother. 2004;2(2):102-11.

47. Hilmer SN, Mager DE, Simonsick EM, Cao Y, Ling SM, Windham BG, et al. A drug burden index to define the functional burden of medications in older people. Arch Intern Med. 2007;167(8):781-7.

48. Normand SL, Sykora K, Li P, Mamdani M, Rochon PA, Anderson GM. Readers guide to critical appraisal of cohort studies: 3. Analytical strategies to reduce confounding. BMJ. 2005;330(7498):1021-3.

49. Hamilton H, Gallagher P, Ryan C, Byrne S, O’Mahony D. Potentially inappropriate medications defined by STOPP criteria and the risk of adverse drug events in older hospitalized patients. Arch Intern Med. 2011;171(11):1013-9.

50. Gallagher PF, O'Connor MN, O'Mahony D. Prevention of potentially inappropriate prescribing for elderly patients: a randomized controlled trial using STOPP/START criteria. Clin Pharmacol Ther. 2011;89(6):845-54.

51. Price SD, Holman CD, Sanfilippo FM, Emery JD. Association between potentially inappropriate medications from the Beers Criteria and the risk of unplanned hospitalization in elderly patients. Ann Pharmacother. 2014;48(1):6-16.

52. Tosato M, Landi F, Martone AM, Cherubini A, Corsonello A, Volpato S, et al. Potentially inappropriate drug use among hospitalised older adults: results from the CRIME study. Age Ageing. 2014;43(6):767-73.

53. Naranjo CA, Busto U, Sellers EM, Sandor P, Ruiz I, Roberts EA, et al. A method for estimating the probability of adverse drug reactions. Clin Pharmacol Ther. 1981;30(2):239-45.

54. Tamblyn R, Abrahamowicz M, du Berger R, McLeod P, Bartlett G. A 5-year prospective assessment of the risk associated with individual benzodiazepines and doses in new elderly users. J Am Geriatr Soc. 2005;53(2):233-41.

55. Samsa GP, Hanlon JT, Schmader KE, Weinberger M, Clipp EC, Uttech KM, et al. A summated score for the Medication Appropriateness Index: development and assessment of clinimetric properties including content validity. $\mathrm{J}$ Clin Epidemiol. 1994;47(8):891-6.

56. Steinman MA, Rosenthal GE, Landefeld CS, Bertenthal D, Kaboli PJ. Agreement between drugs-to-avoid criteria and expert assessments of problematic prescribing. Arch Intern Med. 2009;169(14):1326-32.

57. Koch K, Miksch A, Schurmann C, Joos S, Sawicki PT. The German health care system in international comparison: the primary care physicians' perspective. Dtsch Arztebl Int. 2011;108 (15):255-61. 
58. Mattison ML, Afonso KA, Ngo LH, Mukamal KJ. Preventing potentially inappropriate medication use in hospitalized older patients with a computerized provider order entry warning system. Arch Intern Med. 2010;170(15):1331-6.
59. O’Mahony D, Cherubini A, Petrovic M. Optimizing pharmacotherapy in older patients: a European perspective. Drugs Aging. 2012;29(6):423-5. 